\title{
Educating the Next Generation of Pediatricians in Urban Health Care: The Anne E. Dyson Community Pediatrics Training Initiative
}

\author{
Judith S. Palfrey, MD, Patricia Hametz, MD, Holly Grason, MA, Quimby E. McCaskill, MD, MPH, \\ Gwendolyn Scott, MPA, and Grace W. Chi, SM
}

\begin{abstract}
\begin{tabular}{|c|} 
ABSTRACT \\
\hline
\end{tabular}
To improve the health of children who are exposed to urban health risks, there has been a national recognition of the need for better models of training pediatricians. In 2000, in response to this need, the Dyson Foundation launched a new residents-training model that focuses on community health and advocacy, The Anne E. Dyson Community Pediatrics Training Initiative (the Initiative). The Initiative is made up of 12 programs at ten sites, which are working in their communities to improve the health of the children. At its core are five objectives: to equip residents with tools and knowledge to provide community-based health care, to make use of community resources so that residents learn to practice as medical

home providers, to engage residents in the communities in which they work, to develop meaningful partnerships between departments of pediatrics and their communities, and to enhance pediatrics training through interdisciplinary collaborations among schools and departments. Curricular approaches at the participating sites differ slightly, but all have explicitly incorporated teaching community pediatrics into their standard rotations and continuity clinics. The authors showcase the programs of the Initiative and explore how the programs have sought buy-in from their parent institutions, faculty, residents, and communities.

Acad Med. 2004;79:1184-1191.
\end{abstract}

I n July 2000, the Dyson Foundation of Millbrook, New York launched a large-scale educational experiment in pediatrics residency training, The Anne E. Dyson Community Pediatrics Training Initiative (the Initiative). Twelve pediatrics residency programs are currently in the middle of this venture with the goal of developing "pediatrics

Dr. Palfrey is chief, Division of General Pediatrics, Children's Hospital Boston, Boston, MA and T. Berry Brazelton Professor of Pediatrics, Harvard Medical School. Dr. Hametz is assistant professor of pediatrics, Columbia University College of Physicians and Surgeons and an attending physician at Children's Hospital of NewYork-Presbyterian. Ms. Grason is associate professor of public health and director, Women's $\mathcal{E}$ Children's Health Policy Center at Johns Hopkins Bloomberg School of Public Health. Dr. McCaskill is assistant professor of pediatrics and associate director of the Dyson Initiative in Community Pediatrics, University of Florida, Jacksonville. Ms. Scott is program manager, Anne E. Dyson Community Pediatrics Training Initiative at Harlem Hospital, New York. Ms. Chi is project manager, national program office, Anne E. Dyson Community Pediatrics Training Initiative, Boston, Massachusetts.

Correspondence should be addressed to Dr. Palfrey, The Anne E. Dyson Pediatrics Training Initiative, National Program Office, Children's Hospital Boston, 300 Longwood Avenue, Boston, MA 02115; phone: (617) 3552812; fax: (617) 730-0048. professionals with greater skills and interest in communitybased medicine and advocacy and the capacity to improve the health of the children in their communities."1,2 Although the Initiative is not exclusively focused on urban health, much of the new training involves tools and skills for approaching the problems that confront urban children and youth. In this article, we describe the origin of the Initiative, detail its components, illustrate how the program has garnered buy-in, and discuss how the program fits into the larger national agenda to improve the care of children in our nation's cities.

\section{ORIGIN OF THE INITIATIVE}

Modern life in the urban areas of the United States brings with it many benefits and opportunities, but also inherent risks and health liabilities. Data from the National Center for Health Statistics document that children growing up in urban environments are at higher risk for poor health outcomes such as low birth weight, infant mortality, asthma, lead poisoning, and death by homicide than are young people 
who are raised in the suburbs or in rural areas. ${ }^{3}$ Recognizing that nearly $30 \%$ of U.S. children and youth live in urban areas, ${ }^{4}$ a focus on the relationship between city life and its health consequences for children is warranted. Increasingly, pediatrics educators have been concerned about improving the way interns and residents are taught to care for children in the urban environment. ${ }^{5-7}$

The Community Pediatrics Training Initiative was the brainchild of Dr. Anne E. Dyson, a pediatrician and philanthropist who believed that 21st-century urban health problems such as violence, child abuse, mental health concerns, obesity, eating disorders, and asthma were poorly addressed by unifocal medical approaches. She argued for a fundamental shift in the way pediatricians practice medicine to one that is comprehensive and community based. ${ }^{8}$ She spent the better part of five years gathering information about how her foundation might help to foster that transition.

\section{Community Pediatrics: A New and Powerful Endeavor}

As a member of the American Academy of Pediatrics (AAP) Committee on Community Health, Dr. Dyson was one of the authors of the AAP's community pediatrics statement ${ }^{9}$ and a strong moral and financial supporter of the AAP's Community Access To Child Health (CATCH) program. CATCH physicians practice community pediatrics to eradicate children's health problems at their source. They are not afraid to rally allies among families, community-based organizations, and the larger society.

\section{Establishing Change by Changing the Establishment}

Dr. Dyson recognized in the CATCH program the elements necessary for profound systems reform. For large-scale change to occur, many more pediatricians would need to understand and buy into the principles of community pediatrics. Established medical power players (e.g., academic health centers, health insurers, managed health care organizations, the federal government) would need to shift their sights to include public health, community medicine, and advocacy principles as part and parcel of health care delivery in the United States.

Dr. Dyson was particularly impressed that medical students, residents, fellows, and junior faculty doctors were daring to ask, "Are we providing quality care?" "How well are the children's needs really being met?" They were speaking out, and they were launching new projects, frequently on their own time. "Grassroots initiatives" were capturing the imagination of other students, residents, fellows, and junior faculty. In many academic health centers, Dr. Dyson also encountered faculty members who had tremendous amounts of experience in community pediatrics, but who were having to carry the burden alone. To fight child abuse, support pregnant teens and teen parents, and advocate for the rights of adolescents with HIV, they pushed hard-like Sisyphusagainst the prevailing customs and cultures.

\section{A Different Kind of Doctor}

Dr. Dyson's analysis led her to conclude that one sure way to improve children's health was to prepare "a different kind of doctor." The Dyson Foundation issued a "request for proposal" for a community pediatrics-training project. Twothirds of the nation's pediatrics residency programs submitted letters of intent. Funding was dependent on program size. The first wave of funding totaled approximately $\$ 15$ million, and the second wave of funding amounted to almost half that. Twelve programs at ten sites were selected to participate for five years: Children's Hospital of Philadelphia; Columbia University Community Pediatrics Training Program at Children's Hospital of NewYork-Presbyterian and Harlem Hospital; Indiana University School of Medicine Pediatrics Residency Program; Medical College of Wisconsin Department of Pediatrics, Pediatrics Training Program; University of California, Davis, School of Medicine, Pediatrics Residency Training Program; University of California, San Diego, Department of Pediatrics and the Naval Medical Center Pediatrics Residency Program; University of Florida Health Science Center/Jacksonville Pediatrics Residency Program; University of Hawaii Integrated Pediatrics Residency Program; University of Miami School of Medicine; and University of Rochester School of Medicine. Tragically, Dr. Dyson died of cancer within a few months of the Initiative's beginning.

\section{Objectives and Program Components}

Five core objectives and components form the structure of the project.

\section{To Equip Pediatrics Residents with the Tools and Knowledge They Need to Become Future Professionals Committed to Improving the Health of Their Communities}

Each of the sites has a slightly different curricular design, but all have explicitly incorporated teaching community pediatrics techniques into their standard rotations and continuity clinics. All of the programs emphasize the importance of cultural competency training. They employ block and longitudinal rotations as well as special elective offerings. During the three years of training, the residents in all of the 
programs are required to complete a community-based pediatrics project.

The sites' curricula introduce the residents to the powerful tools now available to address urban health problems. For instance, with the aid of expanded community-focused history forms, emergency room faculty teach residents not only how to find a broken bone but also to discover where the injury occurred and under what circumstances. ${ }^{10}$ The doctors then have the chance to identify faulty equipment on a local playground or pinpoint a particularly unsafe school environment. ${ }^{11}$ Residents are taught to use well-standardized questionnaires such as the CRAFFT, ${ }^{12}$ HEADSS, ${ }^{13}$ and the Advocacy Code Card ${ }^{14}$ to elicit information on significant risk factors. Using these instruments, residents become far more adept at addressing problems such as poor housing, parental depression, substance abuse, and community violence. Recent evidence confirms that families value having their pediatricians ask these types of questions. ${ }^{15,16}$ Through their participation in the Initiative, the residents learn how to prescribe local community resources such as access to food pantries, swimming lessons, after-school activities, and smoking-cessation training.

The residents acquire three critical aspects of communitypediatrics knowledge: (1) a high-level understanding of how community factors determine health, (2) knowledge of how families from different cultural and ethnic backgrounds are affected by societal influences, and (3) knowledge of how larger governmental and political forces shape the reality of the world we live in. Through educational methods such as service learning, they actively explore the role of pediatrics professionals in dealing with those realities.

\section{To Use the Resources of the Local Community to Provide Didactic and Experiential Opportunities in Advocacy and the Assessment of Community Goals, Strengths, and Needs So That the Residents Learn to Practice as Medical Home Providers}

The Initiative's experience-based curriculum teaches residents demographics and health facts about the local area. They learn that a child living in Philadelphia is 1.5 times as likely to have asthma than is a child living in the suburbs (13.7\% versus 9.1\%), ${ }^{17}$ and a baby born in East Harlem, New York is 4.5 times more likely to die in the first year than is a baby born a few blocks away in the Upper East Side (13.3 in 1,000 versus 3 in 1,000). ${ }^{18}$ The residents hear the stories of the immigrant groups who have recently moved into the community, including their encounters with oppression, war, and famine.

To bring these facts alive, the Initiative's curriculum includes tours and immersion opportunities taught by com- munity leaders. Residents become more familiar with asthma, lead poisoning, and injury risk by accompanying communitybased home visitors. They see why an expanded asthma treatment plan calls for a VNA (Visiting Nurse Association) referral, HEPA (high-efficiency particulate air) filters, and bed covers. They contrast the nebulizer treatment in a kitchen crowded with a mom and three children with the same intervention given in the sterile calm of the health office. They witness the substandard housing that many children call home. Their community-based and hospital faculty reinforce their observations and put them into context. Now the statement that there are two million U.S. households where the families report a severe housing problem resonates in a way that the bare fact never would. ${ }^{19}$

Once the residents grapple directly with the interactions between urban conditions and health outcomes, they ask about the next step. The faculty members provide them with training in advocating for change at the state and national legislative level. Some of the residents participate in "legislative days" at their state's capitol and in Washington, D.C. They work with local community agencies to ensure that their patients with special needs receive the highest standard of health care available by using the medical home model. ${ }^{20}$ A medical home provides continuous, comprehensive, coordinated, and culturally effective care, with prompt and effective referral to appropriate specialties. Implementing a medical home puts a family in the center of the delivery of care and allows the agenda of care to be driven by high-priority issues. Physicians engaged with a family in a medical home form partnerships with other professionals and agencies to offer comprehensive, community-based, and culturally responsive services.

\section{To Engage Pediatrics Residents in the Communities in Which They Work}

To be effective in community pediatrics, residents must have more than a passing exposure to the community; they need to engage actively. Working with community partners, families, and pediatrics faculty members, the residents develop and implement discrete projects specifically targeted at diminishing the community-level health risks that members of the community deem most critical. Examples of projects include: Safety First! Promoting Gun Safety Among Pediatricians, Children, and Families; a monthly Spanish-language radio show, Preguntale al Pediatra; a Baby-Friendly ${ }^{\mathrm{TM}}$ Hospital Initiative; and Filling the Cavities Between Children and Oral Health. No predefined script could have brought out the action that giving the residents time, resources, encouragement, and mentorship has allowed. 
4. To Develop Meaningful Partnerships between Academic Departments of Pediatrics (and Their Medical Centers), Community-Based Organizations, Community Pediatricians, and Families in Their Regions

Training in community pediatrics can only occur in environments where there are bona fide relationships with the community and a commitment to a vision of shared responsibility for children's health. By definition, the academic health centers that participate in the Initiative must understand community-level thinking and have an interest in marshalling intellectual and service resources from places not traditionally considered by academic medical centers.

In many cases, capitalizing on these resources means doing something new and potentially risky. The power sharing and choice making with community partners can alienate important people and agencies in the community or even within the academic health center. When grant applications are submitted to philanthropic foundations and the federal government, the money may flow to the community, not to the hospital. Participating in the Initiative also means that academic institutions have to come face-to-face with complex issues such as institutional racism, differential service delivery for private and public patients, priority setting, and local-community engagement as landowners and large-scale employers. ${ }^{21}$

The Initiative specifically calls on academic health centers to form partnerships with local community pediatricians and families. The CATCH program has demonstrated the power that such relationships have for confronting urban health concerns. Making family-centered care a reality is a tall order, but without such a commitment, physicians and nurses will continue to operate without key information and continue to miss high-priority concerns.

\section{To Enhance Pediatrics Training through Interdisciplinary Collaborations with Other Schools and University Departments}

The Initiative challenges the field to look for new ways of responding to the threats facing children and the trials their parents experience. One way to generate those new ideas is to encourage the explicit engagement of colleagues from public health, nursing, dentistry, anthropology, education, and law. This interdisciplinary collaboration is particularly appropriate for enriching and deepening the discipline of community pediatrics. Public health colleagues bring their expertise in epidemiology, needs assessment, and group-level project planning. Colleagues in cultural anthropology help with curricular planning on topics relating to cultural responsiveness and the interactions of culture, environment, and health. Lawyers help with topics relating to social justice, legal rights of individual patients, and legislative and systems change.

\section{Achieving Buy-In for New Urban Health APPROACHES}

Several factors are critical for sustaining community-based health-promotion programming ${ }^{22-24}$ and educational interventions. ${ }^{25,26}$ The political, economic, and administrative actors must be open to and the structures must be congruent with the new program. In addition, champions of the Initiative are necessary to foster both short- and long-term support for the program or project.

At each site, buy-in has been sought explicitly from at least four constituencies: the administration of the pediatrics departments and the medical schools, the pediatrics faculty at large, the residents, and the affiliated community-based organizations. At this point in the Initiative, we can comment on the experience of garnering necessary support from these constituencies.

\section{Administration}

A requirement of Initiative's funding is that each of the academic health centers must indicate their strong commitment to using the Initiative as a catalyst for change. Over the first four years of the Initiative, we have observed the seriousness of this commitment. Two of the large urban hospitals have established hospital-wide efforts in advocacy, creating positions and hiring new staff dedicated to improving the health of children within their communities. Several of the programs have created endowment mechanisms to carry on the community-based work as a core function of their departments. The Initiative's staff have been recognized as valuable players in hospital and medical school efforts to foster better community relations and, in particular, respond to an increasingly diverse patient population.

There is still a long way to go to achieve full administrative buy-in. The day-to-day viability of academic medical centers requires administrators to keep a sharp eye on the bottom line. Reaching out to care for increasing numbers of underserved children in the inner city carries enormous risks. As a result, part of the Initiative's advocacy has focused on identifying funds to support the centers and their partners in this mission. These have included philanthropic gifts, federal grants, funding from conversion foundations, and local city "children's taxes."

\section{Faculty}

Buy-in from pediatrics faculty has turned out to be one of the most gratifying and interesting parts of the Initiative experience to date. The Dyson Initiative National Evaluation suggested high levels of interest and expertise in community 
pediatrics among Dyson faculty, but it also found that most of their efforts are on an off-hours and volunteer basis. ${ }^{2,27}$ Thus, it was not a complete surprise that faculty from throughout the Initiative's training programs have stepped forward to serve as mentors for the residents and to engage more directly with local community-based organizations. The principal investigators from the ten sites represent a wide range of disciplines including general pediatrics, adolescent medicine, emergency medicine, hematology/oncology, renal medicine and developmental psychology. The faculty who currently mentor residents' projects come from neonatology, infectious disease, intensive care, renal medicine, hematology/oncology, as well as general pediatrics, adolescent medicine, and emergency medicine. Each of the sites has explicitly sponsored faculty activities in community medicine to assist the faculty in these efforts.

What has drawn faculty in is the day-to-day usefulness of the Initiative. With its emphasis on cultural competency, the program is improving clinical services through more effective interactions with patients from diverse racial and ethnic groups. In addition, several programs are taking advantage of their participation in the Initiative to upgrade their medical record charting and improve their electronic medical records. Through legislative advocacy by residents, real dollars have been restored into the service sector and new dollars have appeared. In Wisconsin, for example, pediatricians will now be able to apply dental sealants for children and will be paid by Medicaid to do so as a direct result of a resident's community-pediatrics project. Public health contracts and philanthropic donations have bolstered other faculty activities. Each time a resident's community-pediatrics project succeeds, there is a ripple effect promoting increased faculty buy-in.

Faculty development opportunities have also enhanced involvement. Over the course of the Initiative, the combined annual numbers of reported grand rounds, symposia, and short trainings related to community child health offered to faculty tripled between 2001 and 2003. During the same period, there was a five-fold increase in the number of in-depth workshops offered to impart new information and build faculty skills. Two programs reported specific recruiting efforts for faculty with special interest and expertise in community-based child health care. ${ }^{27}$

\section{Residents}

One of the most critical and complicated components of the Initiative has been the residents' buy-in. There are numerous challenges to the integration of such training into the already cramped and demanding lives of pediatrics trainees. To assure that the residents are fully on board with the project, the sites have approached buy-in by involving residents as much as possible in the design of the Initiative's activities.

There is a natural (even ironic) tension built into the Initiative because of the determination to honor residents' autonomy and advocacy. Faculty members encourage the trainees to speak up and to expose any program components they think need fixing. In most of the programs, residents have voiced their criticisms regarding the new training. Early on, residents were disaffected by the teaching and the requirements of the superimposed evaluation. Residents had questions about the value of the training. They wondered if time on the wards or in their continuity clinics was being supplanted by experiences that were less relevant to their careers. What would they learn that they did not already know?

The faculty quickly realized that they had not been effective in providing hard data about the impact of social and environmental factors on children's health outcomes. They recognized the need to tie the lessons from the community experiences directly to the residents' clinical life. For example, once the faculty spelled out the linkage between failure to thrive and food insufficiency, the trip that the residents had made to the storefront food pantry suddenly fell into place. The buy-in for the residents increased as they experienced improvement in their clinical skills and an enhancement of the repertoire of interventions at their disposal. When orienting new residents, they talked about the importance of building true Medical Homes for their patients because of the impact on both their patients and their own satisfaction. In several of the sites, the residents formed their own committees, which have been extremely helpful in improving communication and in establishing goals and priorities for service and for learning.

The residents' buy-in has turned out to be most successful in programs that have actively engaged the chief residents in the leadership of the program. With the service demands on residents and the new 80-hour workweek restrictions, free time is an elusive commodity. The chief residents are in a good position to facilitate the success of the activities by allotting the residents the appropriate time to carry them out. The residents' buy-in has also emerged from the opportunities that residents have had to serve on community boards and coalitions. Through these experiences, individual residents tie the entire program into community-wide initiatives and bring back information to the residency that helps to shape and focus the endeavors of both residents and faculty.

\section{Community Organizations}

The biggest innovation of the Initiative has been the creation of the partnerships with the community-based organizations for the improvement of community health. For ex- 
ample, several of the programs provide medical coverage for homeless shelters under the auspices of a community-based organization. Several of the programs are collaborating with their local Head Start organization and some have relationships with the local schools.

There are challenges to obtaining community buy-in and building and sustaining partnerships. Such challenges are well illustrated by the experience of the Children's Hospital of New York's program in the creation of Access Safety City. To attack the problem of pedestrians' injuries in the Washington Heights community in New York City, residents at Children's Hospital of NewYork-Presbyterian proposed building a Safety City where children and persons with disabilities learn the basics of crossing the street and playing safely in an urban environment. The program depended on the creation of a coalition including the New York City Department of Transportation (DOT), local community stakeholders, and the medical center.

Initially, the coalition building was hampered by a disconnect between partners' agendas, a lack of communication, and a failure to recognize growing problems in a timely manner. The DOT's staff were not accustomed to working with grassroots community agencies, did not appreciate their potential contributions towards fundraising efforts or the importance of local community leaders' and residents' support, and therefore did not facilitate the medical center's efforts to create a coalition. The local community partners were never wholly engaged in the project; local community residents, at least initially, were wary of anyone who wanted to build anything on the lot designated for the project; and they were suspicious of the medical center's and DOT's intentions. There was also confusion within the medical center about which group was responsible for the outreach to the community.

To launch the program, the stakeholders had to find common ground. Through a series of e-mail communications and meetings, the DOT, the medical center, and the community listened and responded to one another's understanding and misunderstanding of how events had transpired. The group defined the role of each partner. In October 2002, Access Safety City opened with a festive ceremony honoring all the partners. The program is now fully operational: The parties continue to work on creating a true partnership, and residents from Children's Hospital of NewYork-Presbyterian participate and learn first hand about the community and primary prevention of injuries to children.

\section{Serving Urban Youth: The National Agenda}

The health care problems of urban youth-particularly asthma, obesity, and mental health concerns-are increasing so rapidly in the United States that the term "epidemic" is in common use. The Anne E. Dyson Community Pediatrics Training Initiative is working in concert with professional associations, advocacy organizations, and government agencies to respond.

Addressing urban health concerns requires new leadership from physicians and others who are competent in epidemiology and needs assessment and who understand public health practice, community-based intervention, and population-based quality management. A national agenda to train new leaders in community health is emerging. Since 1996, the Residency Review Committee has required training in community pediatrics. ${ }^{28}$ The Accreditation Council for Graduate Medical Education's six core competencies emphasize professionalism in medicine and call for a reexamination of physicians' responsibility within the society. ${ }^{29}$ Working with the AAP and the Ambulatory Pediatric Association, the Initiative has promoted the development of these physician-leaders by providing them national visibility at annual association meetings as well as the opportunity to share their experiences and accomplishments. One mechanism for this sharing has been an interactive Web site (〈www.dysonintitiative.org $\rangle$ ) where residents can post information about their projects and others can visit to learn about successful projects. List 1 gives examples of the types of projects in which the residents are engaged. In the near future, this Web site will be merged with that of the residents' section of the AAP to enhance the impact of this synergy.

Several major national reports (the Institute of Medicine, ${ }^{30}$ the Commonwealth Fund, ${ }^{31-33}$ and the Surgeon General's Office ${ }^{34}$ ) have called on academic health centers to engage more proactively in reducing health disparities between rich and poor, white and nonwhite, urban and nonurban populations. The partnerships developed through the Initiative will meet many of the criteria delineated in these reports and may serve as demonstrations of the feasibility of this type of engagement among academic health centers and their neighbors.

To maximize the effect of the training program, the Initiative has explicitly trained the physicians at the sites in comprehensive, state-of-the-art health care delivery. The sites are working to ensure that their health care delivery models can meet the criteria of a medical home. Several of the sites are incorporating the newest guidelines for health promotion and disease prevention into their training and several have continuous quality improvement projects in place. All of the programs emphasize evidence-based medicine.

Finally, the trainees and faculty of the Initiative attack the root causes of urban health problems in children by working in concert with each other and with their community partners and families. The residents are learning how important it is to speak up and to stand as witnesses when they see 


\section{List 1}

Examples of Urban Health Issues Addressed by Pediatrics Residents'
Projects at 12 Programs Taking Part in the Anne E. Dyson Pediatrics
Training Initiative Physical Activity
1. Overweight and obesity
2. Tobacco use
3. Substance abuse
4. Sexual behavior and teen pregnancy
5. Mental health
6. Injury and violence
7. Environmental quality
8. Immunizations
9. Access to care
10. Asthma
11. Children with special health care needs
12. Homelessness
13. Foster care
14. Breastfeeding
15. Postpartum care
16. Parent education
17. Provider education
18. School health
19. Gay/lesbian/transsexual/bisexual youth
20. Oral health
21. Legislative advocacy
22. Literacy

conditions that are harmful to children. As a result, they have learned how to engage legal advocates at the clinical level to help obtain housing, food, and medical insurance for families. They have learned how to write letters to the editor, to their senators, and to their department chairs. They have learned that those letters carry even more weight when health care professionals sign them jointly with communitybased agencies and family members. They have learned that silence gets nothing, and that their voices have authority because they are on the front lines and are seeing the reality that their young patients and their families face. Perhaps the major success of the Initiative to date is that the residents involved know that they are a vital and active part of a larger national agenda to improve the health and well-being of children and youth.

The authors gratefully acknowledge the following individuals for their careful and thoughtful review of this manuscript: Matilde Irigoyen, Nancy Swigonski, Sarah Stelzner, and Earnestine Willis.

The Initiative's principal investigators are Stephen Ludwig, MD, and Donald Schwarz, MD, MPH, Children's Hospital of Philadelphia; Matilde Irigoyen, MD, Dodi D. Meyer, MD, MS, and Stephen W. Nicholas, MD, Columbia University; Stephen Downs, MD, MS, Sarah Stelzner, MD, and Nancy Swigonski, MD, MPH, Indiana University; Earnestine Willis, MD, MPH, Medical College of Wisconsin; Richard Pan, MD, MPH, and Daniel
West, MD, University of California, Davis; Philip R. Nader, MD, Vivian M. Reznik, MD, MPH, and Gregory S. Blaschke, MD, University of California, San Diego, and San Diego Naval Medical Center; Jeffrey Goldhagen, MD, MPH, and Elisa Alter Zenni, MD, University of Florida, Jacksonville; D. Christian Derauf, MD, and Louise Iwaishi, MD, University of Hawaii; Daniel Armstrong, PhD, and Arturo Brito, MD, University of Miami; Jeffrey M. Kaczorowski, MD, Laura Jean Shipley, MD, and Andrew Aligne, MD, $\mathrm{MPH}$, University of Rochester.

The Initiative's Program Advisory Committee is Danny Aronzon, MD, Vassar Brothers Hospital; Joe Carrillo, MD, Children's Hospital Boston; Diana Gurieva, MPH, The Dyson Foundation; Karen Hendricks, JD, American Academy of Pediatrics; Sam Katz, MD, Duke University Medical Center; Woodie Kessel, MD, DHHS; Judy Palfrey, MD, Children's Hospital Boston; Allan Rosenfield, MD, Columbia Public Health; Cal Sia, MD, Hawaii Medical Association; Steve Shelov, MD, MS, Maimonides Medical Center; Tom Tonniges, MD, American Academy of Pediatrics; and Pat Volland, MSW, MBA, New York Academy of Medicine.

\section{REFERENCES}

1. Nader PR, Kaczorowski J, Benioff S, Tonniges T, Schwarz D, Palfrey J; Dyson Community Pediatrics Network. Education for community pediatrics. Clin Pediatr. 2004 43:505-21.

2. Anne E. Dyson Community Pediatrics Training Initiative National Program Office. Caring All Together: A Report of the Anne E. Dyson Community Pediatrics Training Initiative; 2004.

3. National Center for Health Statistics. Health, United States. 2003.

4. United States Census Bureau. United States-Urban/Rural and Inside/ Outside Metropolitan Area. Washington, DC: United States Census Bureau, 2000.

5. Weitzman CC, Freudigman K, Schonfeld DJ, Leventhal JM. Care to underserved children: residents' attitudes and experiences. Pediatrics. 2000;106:1022-7.

6. National Center for Education in Maternal and Child Health. Pediatric Education in Community Settings: A Manual. Arlington: VW, 1996.

7. Institute of Medicine. Who Will Keep the Public Healthy? Educating Public Health Professionals for the 21st Century. Washington, DC: Institute of Medicine of the National Academies Press, November 4, 2002.

8. University of California, San Diego. Anne E. Dyson Community Pediatrics Training Initiative 〈http://www.sdhealth.org/dyson/dyson.html〉. Accessed 16 June 2004.

9. American Academy of Pediatrics. Committee on Community Health Services. The pediatrician's role in community pediatrics. Pediatr. 1999;103:1304-7.

10. Ludwig S. Avoiding missed opportunities in pediatric trauma. Boston Medical Center Joel and Barbara Alpert Lecture in General Pediatrics. Boston, MA, May 13, 2004.

11. Durkin MS, Laraque D, Lubman I, Barlow B. Epidemiology and prevention of traffic injuries to urban children and adolescents. Pediatrics. 1999;103:e74.

12. Knight JR, Shrier LA, Bravender TD, et al. A new brief screen for adolescent substance abuse. Arch Pediatr Adolesc Med. 1999;153: 591-6.

13. Cohen E, Mackenzie RG, Yates GL. HEADSS, a psychosocial risk assessment instrument: implications for designing effective intervention programs for runaway youth. J Adolesc Health. 1991;12:539-44.

14. Fleegler Eric, fellow, Health Services Research, Children's Hospital Boston. Advocacy code card. Personal communication, June 23, 2004.

15. Burdette HL, Whitaker RC, Kahn RS, Harvey-Berino J. Association of maternal obesity and depressive symptoms with television-viewing time 
in low-income preschool children. Arch Pediatr Adolesc Med. 2003; 157:894-9.

16. Wilson CR KJ. When parents have a drinking problem. Contemp Pediatr. 2001;18:67-79.

17. Philadelphia Health Management Corporation. Children and Asthma. Philadelphia: Philadelphia Health Management Corporation, 2002 2003.

18. New York City Department of City Planning. Manhattan Community District Profile. New York; 2002 〈http://www.nyc.gov/html/dcp/pdf/ lucds/mn11profile.pdf). Accessed 16 June 2004.

19. Forum on Child and Family and Statistics. America's Children: Key National Indicators of Well-Being, 1998. Housing Problems. Washington, DC: US Government Printing Office, 1998.

20. The medical home. Pediatr. 2002;110:184-6.

21. Case BG, Himmelstein DU, Woolhandler S. No care for the caregivers: declining health insurance coverage for health care personnel and their children, 1988-1998. Am J Public Health. 2002;92:404-8.

22. Goodman RM SA. The life and death of a health promotion program: an institutional case study. Int Q Community Health Educ. 1987;88:8:5-21.

23. Goodman RM SA. Mobilizing organization for health enhancement: theories of organizational change. In: Glanz LR (ed). Health Behavior and Health Education: Theory, Research and Practice. San Francisco: Jossey-Bass, 1990.

24. Grayson MS, Newton DA, Klein M, Irons T. Promoting institutional change to encourage primary care: experiences at New York Medical College and East Carolina University School of Medicine. Acad Med. 1999;74:S9-15.

25. Harris DL, Henry RC, Bland CJ, Starnaman SM, Voytek KL. Lessons learned from implementing multidisciplinary health professions educational models in community settings. J Interprof Care. 2003;17:7-20.
26. Harris DL, DaRosa DA, Liu PL, Hash RB. Facilitating academic institutional change: redefining scholarship. Fam Med. 2003;35:187-94.

27. Dyson Initiative National Evaluation. Evaluation Report in Anne E. Dyson Community Pediatrics Training Initiative: Caring All Together. Boston: 2004.

28. Residency Review Committee for Pediatrics. Program Requirements for Residency Training in Pediatrics. Accreditation Council for Graduate Medical Education. Chicago, IL, 1996.

29. Accreditation Council for Graduate Medical Education. General Competencies: Minimum Program Requirements Language. 1999. Available at www.acgme.org. Accessed 23 June 2004.

30. Institute of Medicine. Academic Health Centers: Leading Change in the 21st Century. Washington, DC: National Academies Press, July 17, 2003.

31. Task Force in Academic Health Centers, The Commonwealth Fund. Envisioning the Future of Academic Health Centers. 2003. Available at www.cmwf.org. Accessed 23 June 2004.

32. Task Force in Academic Health Centers, The Commonwealth Fund. Training Tomorrow's Doctors: The Medical Education Mission of Academic Health Centers. 2002. Available at www.cmwf.org. Accessed 23 June 2004.

33. Task Force in Academic Health Centers, The Commonwealth Fund. A Shared Responsibility: Academic Health Centers and the Provision of Care to the Poor and Uninsured. 2001. Available at www.cmwf.org. Accessed 23 June 2004.

34. Public Health Service, Office of the Surgeon General, United States Department of Health and Human Services. Closing the Gap: A National Blueprint to Improve the Health of Persons with Mental Retardation. Report of the Surgeon General's Conference on Health Disparities and Mental Retardation. Rockville, MD: 2002. 